\title{
Informed Headquarters and Socialistic Internal Capital Markets
}

\author{
Daniel Hoang and Martin Ruckes \\ Universität Karlsruhe (TH)
}

September 5, 2008

\begin{abstract}
This paper develops a theory of resource allocation in internal capital markets that is consistent with the empirical finding that multi-division firms bias their investment levels in favor of divisions with weaker investment prospects. We characterize an internal capital market as a principal-agent relationship in which headquarters with control rights over internal funds has private information about the relative quality of future investment opportunities of its divisions. Then today's capital allocation may serve as a signal about future ones to divisional managers. To boost managerial effort, headquarters distributes capital relatively evenly.
\end{abstract}

JEL Classification: G31, D82 


\section{Introduction}

Well-functioning internal capital markets channel scarce financial resources into their most productive use. In multi-division firms, headquarters has ownership rights and therefore is able to allocate capital across divisions (Gertner, Scharfstein and Stein, 1994). This allows for steering funds towards divisions with relatively favorable investment opportunities (Stein, 1997). The value of such internal capital markets has been questioned recently, however. Empirical research points towards the distortion of capital allocation in favor of divisions with poor growth prospects relative to those with good growth opportunities (Scharfstein, 1998, Shin and Stulz, 1998, and Rajan, Servaes and Zingales, 2000). ${ }^{1}$

These findings have led to a number of theoretical characterizations of the workings of internal capital markets that are consistent with such "socialistic" allocations of financial resources in internal capital markets. Scharfstein and Stein (2000) argue that managers of divisions with poor investment opportunities have stronger incentives to spend time lobbying to increase their capital allocations. When there is a preference of top management to compensate these managers with capital allocations rather than with higher salaries, this behavior leads to larger than efficient allocations to weaker divisions. Rajan, Servaes and Zingales (2000) show that a very uneven resource allocation can lead divisional managers to steer their investment policies away from efficient cooperative investments towards those that only benefit the own division. To avoid such inefficiencies, headquarters tilts capital allocations towards divisions with fewer investment opportunities. In a setting in which divisional managers have private information about project quality and in addition need to be incentivized to provide effort, Bernardo, Luo and Wang (2006) show that headquarters optimally biases project choice in favor of weaker divisions. The reason is that this allows for less expensive incentive provision for managers in stronger divisions.

This paper provides an alternative explanation of socialistic internal capital markets. We present a model in which headquarters has private information about divisional capital productivity. The argument is as follows: When capital productivity in divisions is persistent, current capital allocations by headquarters are indicative of future allocations. Divisional managers learn from current allocations about their own division's relative capital productivity. When divisional managers prefer larger allocations to smaller ones this is relevant information. The reason is that when managers choose to engage in pro-

\footnotetext{
${ }^{1}$ These empirical studies are not free of measurement and endogeneity problems. Maksimovic and Phillips (2007) provide a comprehensive discussion of those issues in the literature on internal capital markets. Also, plant-level evidence in Maksimovic and Phillips (2002) shows that multi-industry firms reallocate resources in favor of strong divisions in case of positive demand shocks.
} 
ductivity improvements, they do so based on the expected increase in capital allocation that is caused by such efforts. The initial relative captial productivity allows each manager a better estimate of the expected marginal effect of effort provision on her utility. A strategically acting headquarters has an incentive to allocate capital evenly across divisions to suggest equal capital productivity. In this case, managers' expected relative increase in next-period's capital allocation from exerting effort is maximized. The cost of such a policy when divisions differ in their productivity is the currently inefficient capital allocation whereas future capital returns are increased due to larger managerial efforts on productivity improvements. In situations in which effort exertion by divisional managers is sufficiently important, the benefits to headquarters of such an even capital allocation despite productivity differences outweigh its cost. This behavior implies that divisions with better investment opportunities do not receive as much capital as their relative capital productivity would imply.

A number of arguments can be made for the existence of private information of top management (acting as headquarters) vis a vis divisional managers. First, headquarters is well informed about all the divisions of the firm whereas divisional managers have detailed knowledge only about their own divisions. Thus, it is reasonable to assume that headquarters holds better information about the relative productivity of capital across divisions than divisional managers. Second, top management is likely to be better informed about issues that influence the profitability of several divisions such as general economic conditions, political developments, strategic intentions, potential merger opportunities or possible spillovers across divisions. ${ }^{2}$ Such informational advantages often result from top managers' activities beyond the realm of the firm such as board memberships, activities in professional associations or the use of her network of personal contacts. ${ }^{3}$ For reasons of simplicity, we develop a model in which headquarters is better informed about capital productivity than the divisions themselves. However, because divisional managers care exclusively about the amount of capital allocated to their own divisions, only the relative levels of productivity matter for their decisions.

\footnotetext{
${ }^{2}$ The literature on strategic management recognizes the informational advantages of CEOs and other higher-ranked individuals. For example, Mintzberg (1975) sums it up as follows: "The manager may not know everything but typically knows more than subordinates do. Studies have shown this relationship to hold for all managers, from street gang leaders to U.S. presidents."

${ }^{3}$ Mintzberg (1975) finds that the chief executives of his sample averaged 44 percent of their contact time with individuals outside the organization. He writes that “... liaison contacts expose the manager to external information to which subordinates often lack access. Many of these contacts are with managers of equal status, who are themselves nerve centers in their own organization. In this way, the manager develops a powerful database of information."
} 
The argument brought forward in this paper is based on the notion that headquarters' ability to reallocate capital across divisions may stifle managerial initiative. This has also been noted by Brusco and Panunzi (2005) and Gautier and Heider (2006) who assume that effort leads to increased income in the period of its provision. In contrast, Inderst and Laux (2005) model, like we do, managerial effort directed to generating future investment opportunities. Inderst and Laux (2005) show that managerial incentives increase when divisions are more homogeneous. The focus of their paper is, however, not on socialism in capital allocations.

While this paper focuses on asymmetries of information within the firm, these are not the only ones affecting capital allocation. De Motta (2003) and Goel, Nanda and Narayanan (2004) include the impact of informational asymmetries between corporate insiders and financial markets on the distribution of capital across divisions.

\section{The Model}

We model an internal capital market with three agents: headquarters and two divisional managers $i, i=A, B$. There are two periods, $t=1,2$. Agents are risk-neutral. Headquarters distributes a fixed amount of funds $I_{t}$ based on expected performance, i.e. capital productivity $q_{i, t}$, of divisions $A$ and $B$. Available funds $I_{t}>0$ are deterministic and are derived from investments taken in previous periods. There is no access to external finance.

We allow for strictly positive expected investment returns with decreasing returns to scale and assume that divisional periodical payoffs $\Pi_{i, t}$ are given by

$$
\Pi_{i, t}=q_{i, t} I_{i, t}-\frac{1}{2} k I_{i, t}^{2}
$$

where $I_{i, t}$ denotes the period $t$ capital investment in division $i$ and $k>0$ parametrizes returns to scale. Divisional capital productivity $q_{i, t}>1$ depends linearly on a baseline productivity $\bar{q}>1$, which is commonly known, and a productivity parameter $x_{i} \in\{0, \bar{x}\}$, which is private to headquarters. In addition, divisional managers can exert effort in pe$\operatorname{riod} 1, e_{i} \in\{0, \bar{e}\}, \bar{e}>0$, to increase capital productivity of the own division in the subsequent period. In this formulation, effort can be interpreted as engaging in restructuring production or distribution, repositioning part of the product portfolio, mentoring employees, furthering long-term relationships to customers or suppliers, or simply searching for good investment opportunities to be implemented in the upcoming period. Concretely, divisional periodical capital productivities are given by

$$
q_{i, 1}=\bar{q}+x_{i} \text { and } q_{i, 2}=\bar{q}+x_{i}+e_{i} .
$$


We assume that divisions have sufficiently profitable investment opportunities such that available funds are fully invested at each date. For simplicity, we assume that payoffs from investments in $t=1,2$ are additively separable and do not accrue before the end of period 2. Hence, second period payoffs are independent of headquarters' period 1 capital allocation. The interest rate is normalized to zero. Let $\alpha_{t} \in[0,1]$ denote the period $t$ portion of available funds $I_{t}$ invested in division $A$ and $\Pi_{t}\left(\alpha_{t}\right)$ denote headquarter's periodical payoff when it allocates $\alpha_{t}$. Thus, considering equation (1), for all $t=1,2$, $\Pi_{t}\left(\alpha_{t}\right)$ equals

$$
\Pi_{t}\left(\alpha_{t}\right)=q_{A, t} \alpha_{t} I_{t}-\frac{1}{2} k\left(\alpha_{t} I_{t}\right)^{2}+q_{B, t}\left(1-\alpha_{t}\right) I_{t}-\frac{1}{2} k\left(\left(1-\alpha_{t}\right) I_{t}\right)^{2}
$$

In our model divisional managers have empire-building preferences and strictly prefer more capital to less. Concretely, we follow the literature (for example, Harris and Raviv, 1996, De Motta, 2003, and Brusco and Panunzi, 2005) by assuming private benefits $\nu$ proportional to assets under control. We consider the admittedly extreme case in which empire-building motives are sufficiently strong such that no feasible incentive payment can alter managers' behavior (see also Hart and Moore, 1995, Aghion and Tirole, 1997, and Stein, 2002). ${ }^{4}$ Effort creates a private cost to the manager $c\left(e_{i}\right)$ which is $c>0$, if $e_{i}=\bar{e}$ and 0 , if $e_{i}=0$. Consequently, in this two-period setting managers seek to maximize utility described by the sum of private benefits derived from assets under control in both periods less the cost from exerting effort in period 1:

$$
U_{i}\left(e_{i}\right)=\nu\left(I_{i, 1}+I_{i, 2}\right)-c\left(e_{i}\right)
$$

The sequence of actions and events is shown in figure 1.

\footnotetext{
${ }^{4}$ Allowing for effective performance-sensitive contracting obviously improves the opportunities to align managers' interests with those of headquarters. If doing so is costly due to frictions, we are unable to identify a reason why this could structurally affect our results.
} 


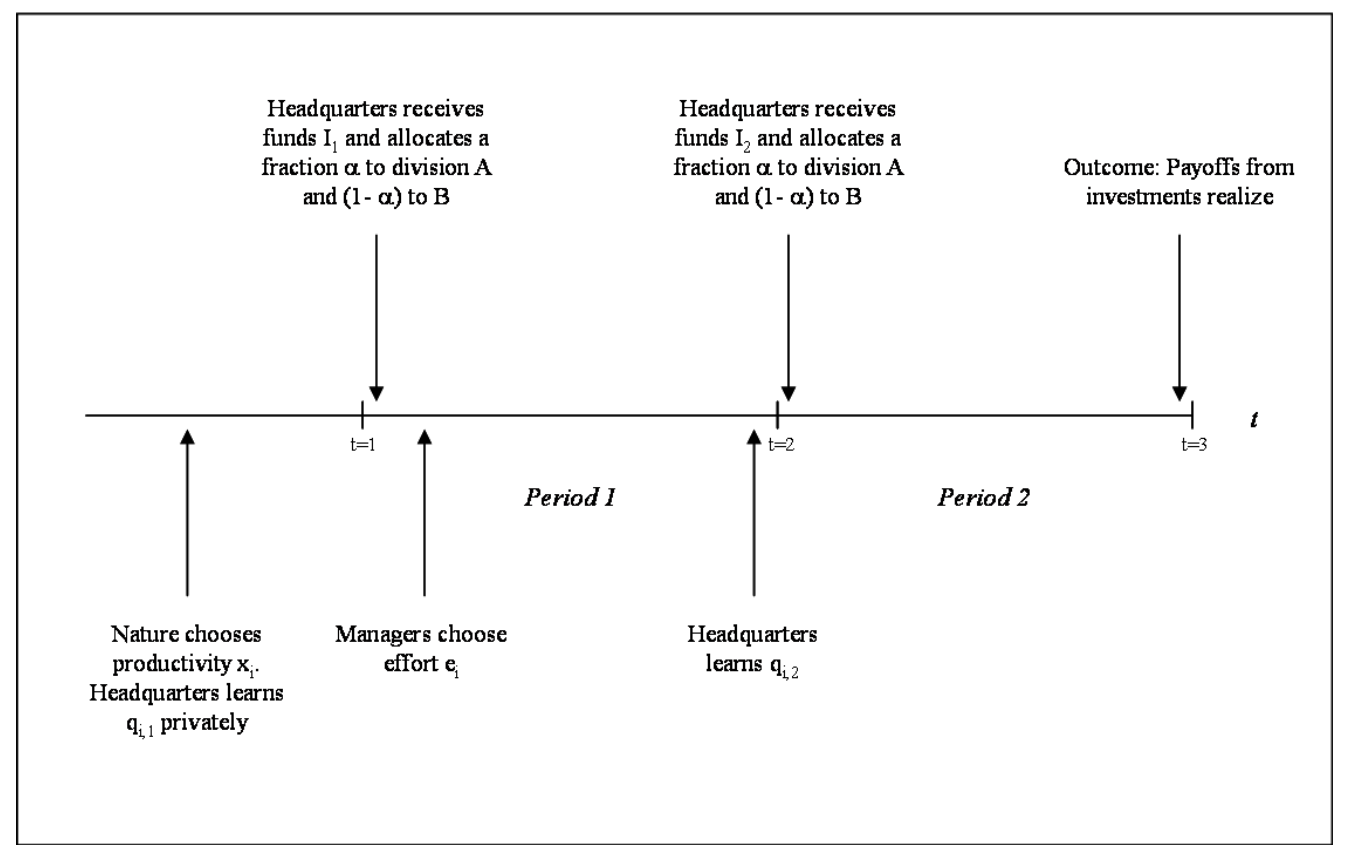

Figure 1: Sequence of Actions and Events

1. Before any capital allocation occurs, headquarters receives a signal $\theta \in\{H, L\}$ that is informative about the true total productivity of investment projects in divisions $A$ and $B$ in $t=1,2$. If headquarters observes

(a) Signal $L: x_{i}$ is equally low $\left(x_{i}=0\right)$ for both divisions; if headquarters observes (b) Signal $H: x_{i}$ is higher for division $A\left(x_{A}=\bar{x}, x_{B}=0\right)$.

This is the simplest way to model asymmetric information between headquarters and divisional managers with respect to relative capital productivities. In the following, we refer to Signal $L$ as headquarters' "type Low" (denoted by $L$ ) and Signal $H$ as its "type High" (denoted by $H$ ).

2. Headquarters distributes available funds $I_{1}$ based on observation of $q_{i, 1}=\bar{q}+x_{i}$.

3. After observing capital allocation $\alpha_{1}$ divisional managers may or may not simultaneously exert effort $e_{i}$. This stage of the model represents a game in which both managers compete for capital to be distributed by headquarters in period 2 .

4. After learning $q_{i, 2}=\bar{q}+x_{i}+e_{i}$, headquarters allocates available funds $I_{2}$. Distribution of funds now depends on managers' effort levels $e_{i}$.

5. At the end of period 2, payoffs $\Pi_{i, t}$ from investments taken in the previous periods realize. 
As it is apparent from the sequence of the game and since we assume that periods are additively separable, headquarters' two-period decision problem simplifies into a pair of problems, one for each period. We can write headquarters' total payoff as $\Pi_{1}\left(\alpha_{1}\right)+\Pi_{2}\left(\alpha_{2}\right)$.

\section{Analysis}

In the next sections we examine optimal capital allocation of headquarters and equilibrium behavior of divisional management. We decompose the analysis of two-period capital allocation into three stages: A first stage, in which headquarters chooses period-1 capital allocation, a second stage, in which divisional managers follow with their effort decision, and a third stage, in which headquarters makes its period-2 capital allocation choice after productivity-enhancing activities of divisional management have realized. Since equilibrium behavior is sequentially rational, we solve the game backwards, beginning with headquarters' period-2 capital allocation. We restrict our attention to pure strategy equilibria.

\subsection{Capital Allocation in Period 2}

By the beginning of period 2, headquarters learns period 2 productivity of its divisions $q_{i, 2}$ with certainty. Hence, headquarters solves:

$$
\max _{\alpha_{2}} q_{A, 2} \alpha_{2} I_{2}-\frac{1}{2} k\left(\alpha_{2} I_{2}\right)^{2}+q_{B, 2}\left(1-\alpha_{2}\right) I_{2}-\frac{1}{2} k\left[\left(1-\alpha_{2}\right) I_{2}\right]^{2}+\Pi_{1}\left(\alpha_{1}\right)
$$

subject to

$$
\alpha_{2} \in[0,1]
$$

Considering the strict concavity of (5), the optimal rule for capital allocation in period 2 is:

$$
\alpha_{2}^{*}= \begin{cases}0 & \text { if } q_{B, 2}-q_{A, 2} \geq k I_{2} \\ 1 & \text { if } q_{A, 2}-q_{B, 2} \geq k I_{2} \\ \frac{q_{A, 2}-q_{B, 2}+k I_{2}}{2 k I_{2}} & \text { otherwise, }\end{cases}
$$

which implies that headquarters shifts all funds to division $i$ if $q_{i, 2}$ relative to $q_{j, 2}$ is sufficiently large and headquarters evenly splits funds if $q_{A, 2}=q_{B, 2}$. Using equation (2) establishes the following lemma. 
Lemma 1 In period 2, headquarters' allocation is a function of managerial effort $e_{i}$, the type-dependent value of $x_{i}$, and the level of level of diminishing returns to scale $k$.

$$
\alpha_{2}^{*}=\left\{\begin{array}{ll}
0 & \text { if } e_{B}-e_{A}-x_{i} \geq k I_{2} \\
1 & \text { if } e_{A}-e_{B}+x_{i} \geq k I_{2} \\
\frac{e_{A}-e_{B}+x_{i}+k I_{2}}{2 k I_{2}} & \text { otherwise }
\end{array} .\right.
$$

Exerting effort weakly increases a manager's own capital allocation and thereby weakly decreases the other manager's allocation. In addition, period 2 capital allocation, say to division $A, \alpha_{2}^{*}$, weakly increases in $\bar{x}$ and weakly decreases in $k$.

\subsection{Managerial Effort in Period 1}

We turn to the previous stage of the game in which managers choose period 1 effort levels $e_{i}$. Divisional management anticipates that headquarters reacts optimally given profitabilities $q_{i, 2}$ and allocates capital according to (7). Since funds $I_{2}$ are scarce, managers compete for their share of the limited total capital budget. This competition for funds represents a game of incomplete information: Each manager chooses whether to exert effort or not while being uncertain about the (type-dependent) value of $x_{i}$ and the (unobservable) effort choice of her counterpart.

To examine equilibrium strategies, we first solve for managers' effort choice as if headquarters' type was common knowledge. Then, this stage of the model becomes a game of complete information and for the effort pair $\left(e_{1}^{*}, e_{2}^{*}\right)$ to be a Nash equilibrium of this subgame, each manager's strategy is a best response to the other's, while considering headquarters' optimal allocation on arbitrary levels of effort. Given the structure of our model, managements' strategy under incomplete information follows immediately.

\section{Common Knowledge: Headquarters is Type $L$}

When headquarters is type $L$ and $x_{A}=x_{B}=0$, intrinsic capital productivities of divisions are identical. Hence, utility functions of managers are symmetric. When managers work equally intense, the contest ends as a tie, headquarters equally splits funds in period 2 and both managers receive payoffs that yield $\frac{1}{2} \nu I_{2}$. Otherwise, the manager who works hard receives strictly more funds than the other. For the sake of expositional tractability and without loss of generality, let $\bar{e} \geq k I_{2}$. Then, if one divisional manager chooses a high level of effort and the other does not, headquarters allocates total available funds to the former and zero funds to the latter. The normal-form of this subgame is given as in figure 2. By convention, managers $A$ and $B$ represent the row and column players, respectively. 


\begin{tabular}{ccc|cc|}
\multicolumn{2}{c}{$\bar{e}$} & \multicolumn{2}{c|}{0} \\
\cline { 2 - 5 } $\bar{e}$ & $\frac{1}{2} \nu I_{2}-c$ & $\frac{1}{2} \nu I_{2}-c$ & $\nu I_{2}-c$ & 0 \\
\cline { 2 - 5 } 0 & 0 & $\nu I_{2}-c$ & $\frac{1}{2} \nu I_{2}$ & $\frac{1}{2} \nu I_{2}$ \\
\cline { 3 - 5 } & &
\end{tabular}

Figure 2: Competition for funds when headquarters is type $L$

Thus, if the cost of managers' effort is sufficiently small compared to their empire-building preferences and

$$
\frac{1}{2} \nu I_{2}-c>0 \quad \Leftrightarrow \quad c<\frac{1}{2} \nu I_{2}
$$

$e_{i}^{*}=\bar{e}$ is the dominant strategy for each player and the effort pair $(\bar{e}, \bar{e})$ is a unique Nash equilibrium of this subgame. Then, it turns out that managers have an incentive to work hard and managers' interest is aligned with headquarters' in order to maximize firm profits. For the remainder of this paper, we assume that equation (8) holds.

\section{Common Knowledge: Headquarters is Type $H$}

When headquarters is type $H$ and $x_{A}=\bar{x} \wedge x_{B}=0$, intrinsic capital productivities of divisions differ in favor of division $A$. Hence, utility functions of managers are asymmetric. When managers exert equal effort, $\alpha_{2}^{*}>0.5$ and headquarters allocates strictly more to division $A$. We make the simplifying assumption that diversity in productivities $\bar{x}$ dominates effort and $\bar{x}-\bar{e} \geq k I_{2}$. Then, the more profitable division $A$ receives all funds regardless of whether its manager works hard or not. More precisely, profitability of division $A$ relative to that of $B$ is sufficiently distant, that marginal return on the last unit $I_{2}$ invested in $A$ is strictly smaller than the marginal return on the first unit invested in $B$. This straightforwardly captures the disincentive effect of headquarters' authority to allocate scarce resources to the most profitable projects as suggested by Brusco and Panunzi (2005) and Inderst and Laux (2005). It also cuts down the number of different cases to be considered without changing the important conclusions. ${ }^{5}$ The winner of the game, manager $A$, is determined ex ante and both managers do not exert effort in equilibrium, $e_{i}^{*}=0$, as long as $c>0$. The subgame can be represented as in figure 3 .

\footnotetext{
${ }^{5}$ The loss of managerial incentives associated to winner-picking in general results from lower marginal benefits of increased effort to marginal costs when managers have identical capabilities but the "rules of the game" favor one of them. Tournament-style models produce a similar result when contestants have unequal chances to win (see e.g. Lazear and Rosen, 1981, and O'Keeffe, Viscusi, and Zeckhauser, 1984.)
} 


\begin{tabular}{|c|c|c|c|c|}
\hline & \multicolumn{2}{|c|}{$\bar{e}$} & \multicolumn{2}{|c|}{0} \\
\hline $\bar{e}$ & $\nu I_{2}-c$ & $-c$ & $\nu I_{2}-c$ & 0 \\
\hline 0 & $\nu I_{2}$ & $-c$ & $\nu I_{2}$ & 0 \\
\hline
\end{tabular}

Figure 3: Competition for funds when headquarters is type $H$

Let us now examine equilibrium effort levels in the more interesting case in which information on productivity $x_{i}$ is private to headquarters and managers have incomplete information on true investment prospects.

\section{Incomplete Information: Headquarters' Type is Private Information}

Under incomplete information, managers do not know (either their "opponent's" or their own) true productivities ex ante, which implies that managers are unable to distinguish one type of headquarters from the other. Let $p(L)=\mu$ and $p(H)=1-\mu$ denote managements' common prior belief about headquarters' type.

Before choosing $e_{i}$, managers observe headquarters' current capital allocation $\alpha_{1}$. When capital productivity in divisions is persistent, this is relevant information: $\alpha_{1}$ is indicative of future allocations. Hence, divisional managers may learn from current allocations about headquarters' private information and may update prior probabilities about headquarters' type. For example, a particular capital allocation may reveal to managers that headquarters is type $L$ and, thus, implies that managers choose to exert effort. However, other allocations may not disclose additional information. We denote the resulting posterior beliefs as $p\left(L \mid \alpha_{1}\right)=\eta\left(\alpha_{1}\right)$ and $p\left(H \mid \alpha_{1}\right)=1-\eta\left(\alpha_{1}\right)$.

As diverse intrinsic profitabilities (a type $H$ headquarters) weaken managerial incentives to engage in productivity-enhancing activities, the equilibrium effort a manager is willing to exert depends on posterior beliefs. To make this point clear, consider for example manager $B$. When both managers exert effort, $e_{i}=\bar{e}$, manager $B$ has the chance to end up in a tie and receive $\frac{1}{2} I_{2}$ with probability $\eta\left(\alpha_{1}\right)$ (since headquarters is type $L$ ) but also faces the risk of losing and getting nothing with probability $1-\eta\left(\alpha_{1}\right)$ (since headquarters is type $H$ ). Thus, managers are uncertain about both, their opponent's and their own payoff function. By applying this logic to all possible payoffs of this subgame, managers' competition for funds can be represented as in figure 4 . For brevity, we omit parameter $\alpha_{1}$ on the posterior $\eta\left(\alpha_{1}\right)$. 


\begin{tabular}{|ccc|cc|}
\multicolumn{2}{c}{$\bar{e}$} & \multicolumn{2}{c|}{0} \\
\cline { 2 - 5 } $\bar{e}$ & $\nu I_{2}-\frac{1}{2} \eta \nu I_{2}-c$ & $\frac{1}{2} \eta \nu I_{2}-c$ & $\nu I_{2}-c$ & 0 \\
\cline { 2 - 5 } 0 & $(1-\eta) \nu I_{2}$ & $\eta \nu I_{2}-c$ & $\nu I_{2}-\frac{1}{2} \eta \nu I_{2}$ & $\frac{1}{2} \eta \nu I_{2}$ \\
\cline { 2 - 5 }
\end{tabular}

Figure 4: Competition for funds under incomplete information

It is straightforward to derive equilibrium effort levels. Our results are given in the following lemma.

Lemma 2 Posterior beliefs reflect any information conveyed by headquarters' capital allocation in period 1. Equilibrium effort levels $\left(e_{A}^{*}, e_{B}^{*}\right)$ are sensitive to these and weakly increase with the belief that headquarters is type $L$

$$
\left(e_{A}^{*}, e_{B}^{*}\right)= \begin{cases}(\bar{e}, \bar{e}) & \text { if } 2 \frac{c}{\nu I_{2}} \leq \eta \leq 1 \\ (0,0) & \text { if } 0 \leq \eta<2 \frac{c}{\nu I_{2}}\end{cases}
$$

The intuition is as follows: When managers with empire-building tendencies choose to engage in productivity improvements, they do so based on the expected increase in capital allocation that is caused by such efforts. The incentive to choose a high level of effort is strong provided that posterior beliefs suggest that heterogeneous productivity across divisions is not too likely. In addition, cost of effort $c$ must be sufficiently low relative to empire-building benefits $\nu I_{2}$; then, even a small posterior belief $p\left(L \mid \alpha_{1}\right)=\eta\left(\alpha_{1}\right)$ induces managers to work hard.

\subsection{Capital Allocation in Period 1}

We now move to the first stage of the game in which headquarters decides on its optimal capital allocation in period 1 . We begin by studying optimal capital allocation in the complete information case. Thereby, we refer to the situation in which managers' productivity is common knowledge. This characterization is then used to examine capital allocation in situations in which information on productivities is private to headquarters and managers are unable to distinguish headquarters' type. 


\subsubsection{The Benchmark Case: Complete Information}

Since periods are additively separable we can derive the optimal capital allocation $\alpha_{1}^{*}$ under complete information simply from maximizing $\Pi_{1}\left(\alpha_{1}\right)+\Pi_{2}\left(\alpha_{2}\right)$ with respect to $\alpha_{1}$. Analogously to (6), $\alpha_{1}^{*}$ depends on marginal returns in divisions $A$ and $B$. The difference is that returns are exogenously given and hence independent from other decisions. Considering that $\alpha_{1} \in[0,1]$, we obtain

$$
\alpha_{1}^{*}=\left\{\begin{array}{cl}
\frac{1}{2} & \text { if headquarters is type } L \\
\min \left\{\frac{\bar{x}+k I_{1}}{2 k I_{1}}, 1\right\} & \text { if headquarters is type } H .
\end{array}\right.
$$

Hence, if headquarters is type $L$, headquarters' efficient allocation is to split funds evenly since marginal divisional returns are identical and strictly decreasing. If headquarters is type $H, \alpha_{1}^{*} \in(0.5,1]$. To simplify the presentation of our results, we set $\bar{x} \geq k I_{1}$. Then, headquarters invests all available funds in division $A$. Using the findings of the previous section, we can establish the following result.

Proposition 1 Under the assumptions previously imposed, there is a unique subgame perfect equilibrium of the game under complete information. Subgame perfect equilibrium behavior $\left(\alpha_{1}^{*},\left(e_{A}^{*}, e_{B}^{*}\right), \alpha_{2}^{*}\right)$ is given by

$$
\left(\alpha_{1}^{*},\left(e_{A}^{*}, e_{B}^{*}\right), \alpha_{2}^{*}\right)=\left\{\begin{array}{l}
\left(\frac{1}{2},(\bar{e}, \bar{e}), \frac{1}{2}\right) \quad \text { if headquarters is type } L \\
(1,(0,0), 1) \text { if headquarters is type } H
\end{array}\right.
$$

Using these results, period 2 firm profits yield

$$
\begin{array}{ll}
\Pi_{L, 2}^{*}=\Pi_{L, 2}^{*}\left(\alpha_{2}^{*}, e_{A}^{*}, e_{B}^{*}\right)=(\bar{q}+\bar{e}) I_{2}-\frac{1}{4} k I_{2}^{2} & \text { if headquarters is type } L \\
\Pi_{H, 2}^{*}=\Pi_{H, 2}^{*}\left(\alpha_{2}^{*}, e_{A}^{*}, e_{B}^{*}\right)=(\bar{q}+\bar{x}) I_{2}-\frac{1}{2} k I_{2}^{2} \quad \text { if headquarters is type } H
\end{array}
$$

and total expected payoffs result in

$$
\begin{aligned}
& \Pi_{L}^{*}=\Pi_{L, 1}^{*}+\Pi_{L, 2}^{*}=\bar{q}\left(I_{1}+I_{2}\right)+\bar{e} I_{2}-\frac{1}{4} k\left(I_{1}^{2}+I_{2}^{2}\right) \\
& \Pi_{H}^{*}=\Pi_{H, 1}^{*}+\Pi_{H, 2}^{*}=(\bar{q}+\bar{x})\left(I_{1}+I_{2}\right)-\frac{1}{2} k\left(I_{1}^{2}+I_{1}^{2}\right) .
\end{aligned}
$$

Consequently, when productivities of divisions are common knowledge among headquarters and managers, our model implies: If divisions differ in their investment opportunities (type $H$ ), headquarters uses its allocative authority and consistently steers all funds to 
its strongest division $A$. Managers foresee headquarters' optimal strategy correctly anticipating that effort has no impact on ex ante predetermined capital allocation. Hence there is no incentive for either manager to be productive. In contrast, if investment opportunities of divisions are similar (type $L$ ), headquarters' right to allocate funds to its most productive use creates the incentive for managers to work hard. In both periods headquarters allocates capital evenly.

\subsubsection{Capital Allocation with Incomplete Information}

3.3.2.1 Perfect Bayesian Equilibria and Refinements Under incomplete information our model conceptually defines a signaling game. Informed headquarters moves first with its period 1 allocations which may reveal additional information. Then uninformed managers update their beliefs about headquarters' type and react conditioned on these allocations according the policy described by Lemma 1. Throughout this section we employ the notion of Perfect Bayesian Equilibrium.

Definition 1 In our model a Perfect Bayesian Equilibrium (PBE) is a set of strategies and a belief function $\eta\left(\alpha_{1}\right) \in[0,1]$ satisfying each of the following conditions: ${ }^{6}$

1. For each type $\theta$, headquarters' strategy is optimal given managers' strategies and managers' posterior beliefs.

2. Both managers share a common posterior belief which is derived from the prior belief $p(L)=\mu$ and headquarters' allocation $\alpha_{1}$, following Bayes' rule where applicable.

3. For each choice of $\alpha_{1}$, managers' effort levels following $\alpha_{1}$ constitute a Nash equilibrium of a simultaneous-move game in which the probability that managers face a type $L$ headquarters is given by their posterior belief $\eta\left(\alpha_{1}\right)$.

Condition (2) implies that when $\alpha_{1}$ is not part of headquarters' optimal strategy for some type, any belief $\eta\left(\alpha_{1}\right)$ is admissible since in equilibrium observing $\alpha_{1}$ is a zero probability event and beliefs cannot be derived following Bayes' rule. Thus, any effort pair $\left(e_{1}, e_{2}\right)$ may be played as long as it is a best response for some beliefs. In our model beliefs are common knowledge between all players. In addition, managers' beliefs are identical after any message, not just an equilibrium allocation. Condition (3) says, that

\footnotetext{
${ }^{6}$ For simplicity, we omit formal definitions and rather provide an intuitive description of the game. We translate our statements into formal definitions if necessary.
} 
given headquarters' allocation $\alpha_{1}$ and given their updated posterior beliefs $\eta\left(\alpha_{1}\right)$ about $\theta$, managers react optimally to headquarters' allocation $\alpha_{1}$.

We determine the set of separating and pooling equilibria in pure strategies. In a separating equilibrium, both types of headquarters choose different allocations and managers can learn headquarters' type. In contrast, in a pooling equilibrium, both types of headquarters set the same allocation and managers can infer nothing from the allocation. As usual a multiplicity of equilibria arises since PBE does not impose any restrictions on managers' beliefs following out-of-equilibrium allocations. To provide sharp predictions on likely equilibrium outcomes, we restrict the set of out-of-equilibrium beliefs applying two well-known refinements: the notions of Undefeated Equilibrium introduced by Mailath, Okuno-Fujiwara and Postlewaite (1993) and D1 as introduced by Cho and Kreps (1987). ${ }^{7}$

In our model Undefeated Equilibrium intuitively applies as follows: Consider a proposed $\mathrm{PBE}^{8}$, some out-of-equilibrium allocation $\alpha$ not chosen in this equilibrium as well as an alternative $\mathrm{PBE}$ in which some set of headquarters' type $T$ plays $\alpha$ in equilibrium. If each member of $T$ strictly prefers the alternative equilibrium to the proposed one, the latter is said to be defeated. ${ }^{9}$

D1, which is based on the idea of Divinity (Banks and Sobel, 1987), is implied by Strategic Stability introduced by Kohlberg and Mertens (1987) and tests if an out-of-equilibrium deviation $\alpha$ is more likely to come from some headquarters' type $i$ than from type $j$ and if so, managers should not put any probability on $j$, hence $p(j \mid \alpha)=0$. Applying $D 1$, an out-of-equilibrium deviation is said to be more likely to occur from type $i$ if the set of managers' best responses which motivate $i$ to deviate is strictly larger than the one which motivate type $j$.

Refinement $D 1$ puts restrictions on out-of equilibrium beliefs focusing on one single equilibrium, while Undefeated Equilibrium compares among equilibrium outcomes and therefore requires the characterization of the full set of PBE (considering all degrees of freedom with respect to out-of-equilibrium beliefs). Consequently, we start with the analysis of Perfect Bayesian Equilibria.

\footnotetext{
${ }^{7}$ For the joint relevance of both refinement concepts in an evolutionary model of job-market signaling see Nöldeke and Samuelson (1997).

${ }^{8}$ In general, Undefeated Equilibrium is applied to the notion of Sequential Equilibrium (Kreps and Wilson, 1982). In our game PBE and Sequential Equilibria coincide (see Fudenberg and Tirole, 1991).

${ }^{9}$ This definition of Undefeated Equilibrium is valid since our model allows us to avoid issues connected with payoff ties of headquarters' types. For a general definition, the reader is referred to the original work.
} 


\subsubsection{Pooling Perfect Bayesian Equilibria}

We begin with a characterization of the set of pooling equilibria. We resume the notation of the previous sections - it is helpful to recall that $\Pi_{\theta, 2}^{*}$ refers to type $\theta$ 's period 2 equilibrium profit under complete information. Let $\Pi_{\theta, 1}(\alpha)$ denote type $\theta$ 's period 1 profit when it allocates $\alpha$.

In a pooling equilibrium, both types of headquarters choose $\alpha^{p}$ and managers learn nothing from capital allocation. ${ }^{10}$ Bayesian updating implies that managers' beliefs after observing $\alpha^{p}$ equal the prior belief, $p\left(L \mid \alpha^{p}\right)=\mu$. Off-equilibrium beliefs $p(L \mid \hat{\alpha})$ are arbitrary as long as beliefs and corresponding off-equilibrium allocations $\hat{\alpha} \neq \alpha^{p}$ deter both types from deviating from $\alpha^{p}$. We assume that a-priori probabilities

$$
p(L)=\mu>2 \frac{c}{\nu I_{2}},
$$

such that managers' best response after observing $\alpha^{p}$ is to exert effort $e_{i}=\bar{e}^{11}$ We hence obtain type $\theta$ 's pooling profits $\Pi_{\theta}^{P}$ :

$$
\begin{aligned}
\Pi_{H}^{P} & =\Pi_{H, 1}\left(\alpha^{p}\right)+\Pi_{H, 2}^{*}+\bar{e} I_{2} \\
\Pi_{L}^{P} & =\Pi_{L, 1}\left(\alpha^{p}\right)+\Pi_{L, 2}^{*}
\end{aligned}
$$

The easiest way to support $\alpha^{p}$ as equilibrium allocation is to restrict off-equilibrium beliefs such that managers decide to do nothing unless they observe $\alpha^{p}$. Then, off-equilibrium payoffs are lowest and deviating is least beneficial for any type of headquarters. We set $p(L \mid \alpha)=\eta(\alpha)=0$ for any $\alpha \neq \alpha^{p}$ as this belief function supports the largest set of pooling equilibria; and, to determine the set of admissible $\alpha^{p}$, we maximize over all potential offequilibrium allocations to solve for the highest out-of-equilibrium allocation under these beliefs. Thus, for any pooling equilibrium choice $\alpha^{p}$, the following conditions must apply:

$$
\begin{aligned}
& \Pi_{H, 1}\left(\alpha^{p}\right)+\Pi_{H, 2}^{*}+\bar{e} I_{2} \geq \max _{\alpha} \Pi_{H, 1}(\alpha)+\Pi_{H, 2}^{*} \\
& \Pi_{H, 1}^{*}-\Pi_{H, 1}\left(\alpha^{p}\right) \leq \bar{e} I_{2} \\
& \Pi_{L, 1}\left(\alpha^{p}\right)+\Pi_{L, 2}^{*} \geq \max _{\alpha} \Pi_{L, 1}(\alpha)+\Pi_{L, 2}^{*}-\bar{e} I_{2} \\
& \Pi_{L, 1}^{*}-\Pi_{L, 1}\left(\alpha^{p}\right) \leq \bar{e} I_{2}
\end{aligned}
$$

Both conditions characterize an interval of allowable $\alpha^{p} \in\left[\underline{\alpha}^{p}, \bar{\alpha}^{p}\right]$ where $\underline{\alpha}^{p} / \bar{\alpha}^{p}$ denotes the lower/upper bound of the interval solving $(11) /(12) .{ }^{12}$ We illustrate this formulation

\footnotetext{
${ }^{10}$ We disregard index $t$ since we made period 2 allocations implicit in managers' tournament for funds.

${ }^{11}$ For completeness, we examine the case in which condition (10) is violated in section 5.

${ }^{12}$ The proof is quite straightforward considering the strict convexity of the left-hand-side of inequalities (11) and (12), type $H$ 's and type $L$ 's full information choices at $\alpha_{1}^{*}=1$ and $\alpha_{1}^{*}=0.5$ as well as the resulting single-crossing point of $\Pi_{L, 1}^{*}-\Pi_{L, 1}\left(\alpha^{p}\right)$ and $\Pi_{H, 1}^{*}-\Pi_{H, 1}\left(\alpha^{p}\right)$ on the interval $(0.5,1)$.
} 
in figure 5 considering the interesting case in which

$$
\Pi_{H, 1}^{*}-\Pi_{H, 1}\left(\alpha^{p}=0.5\right)<\bar{e} I_{2}
$$

When (13) does not hold, type $H$ has no incentive to imitate $L$ 's full information allocation $\alpha_{1}^{*}=0.5$ as the cost from moving away from its full information optimum, $\Pi_{H, 1}^{*}-\Pi_{H, 1}\left(\alpha_{1}=\right.$ $0.5)$ outweighs the gain from imitating type $L, \bar{e} I_{2}$. In this case, both types of headquarters are better off by following their full information strategy. If condition (13) is met, a pooling equilibrium always exists since $\bar{e} I_{2}$ relative to headquarter's cost from inefficient investment at the crossing point of both curves is sufficiently high and also implies that condition (12) is non-binding. ${ }^{13}$ Hence, we obtain a continuum of pooling equilibrium allocations $\alpha^{p}$ on the interval $\left[\underline{\alpha}^{p}, \bar{\alpha}^{p}\right]$, where $\underline{\alpha}^{p}<0.5$ and $\bar{\alpha}^{p}=1$.

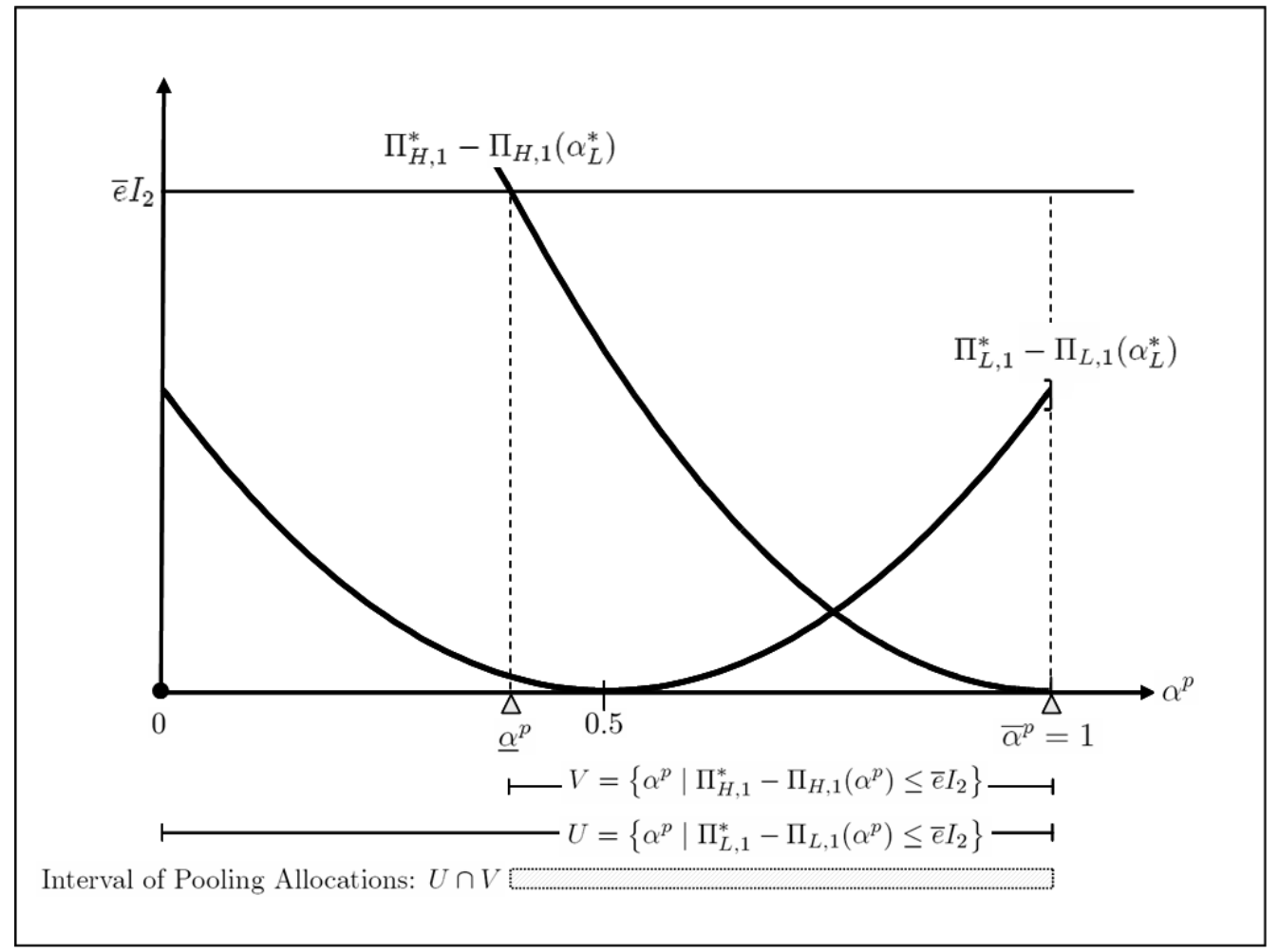

Figure 5: Interval of Pooling Allocations $\alpha_{P}$

Consequently, inequalities (11) and (12) completely characterize the set of pooling equilibrium allocations. The easiest way to support these equilibria is to make out-of equilibrium outcomes small by setting $p(L \mid \alpha)=\eta(\alpha)=0$, for any out-of-equilibrium allocations $\alpha \neq \alpha^{p}$. However, any other belief which does not motivate some type of headquarters to deviate from its equilibrium allocation is also admissible.

\footnotetext{
${ }^{13} \mathrm{It}$ is easily shown that $\Pi_{H, 1}^{*}-\Pi_{H, 1}\left(\alpha^{p}=0.5\right) \geq \Pi_{L, 1}^{*}-\Pi_{L, 1}\left(\alpha^{p}=0\right) \Leftrightarrow \frac{1}{2} \bar{x} I_{1}-\frac{1}{4} k I_{1}^{2} \geq \frac{1}{4} k I_{1}^{2}$ always holds given the assumption that $\bar{x} \geq k I_{1}$.
} 


\subsubsection{Separating Perfect Bayesian Equilibria}

So far we have considered equilibria in which managers remain uninformed after observing headquarters' period 1 choice. Let us now characterize the set of separating equilibria. $\alpha_{L}^{*}$ denotes a separating equilibrium allocation, if headquarters is type $L$, and $\alpha_{H}^{*}$, if headquarters is type $H$. We show that in any separating equilibrium a type $H$ headquarters chooses $\alpha_{H}^{*}=1$, i.e. distributes all funds to its most profitable division $A$, while a type $L$ headquarters selects an allocation $\alpha_{L}^{*}$ which belongs to an interval - depending on firm's specific conditions and managers' belief function.

In a separating equilibrium, headquarters' private information is revealed by its period 1 allocation. Posterior beliefs yield $\eta\left(\alpha_{L}^{*}\right)=1$ and $\eta\left(\alpha_{H}^{*}\right)=0$ and managers react optimally as under complete information. For the equilibrium to be separating, we must guarantee that $\alpha_{L}^{*} \neq \alpha_{H}^{*}$ and assure that allocations are incentive compatible. This implies that a type $H$ headquarters does not want to pick type $L$ 's allocation and vice versa. In addition, off-equilibrium allocations (i.e. allocations that differ from both equilibrium choices) and corresponding beliefs must deter both types from deviating from their equilibrium action.

In a separating equilibrium each type prefers its own allocation as long as the following incentive-compatibility constraints apply:

$$
\begin{gathered}
\Pi_{H, 1}\left(\alpha_{H}^{*}\right)+\Pi_{H, 2}^{*} \geq \Pi_{H, 1}\left(\alpha_{L}^{*}\right)+\Pi_{H, 2}^{*}+\bar{e} I_{2} \\
\Pi_{L, 1}\left(\alpha_{L}^{*}\right)+\Pi_{L, 2}^{*} \geq \Pi_{L, 1}\left(\alpha_{H}^{*}\right)+\Pi_{L, 2}^{*}-\bar{e} I_{2}
\end{gathered}
$$

Under incomplete information a type $H$ headquarters, for instance, could deploy type $L$ 's allocation $\alpha_{L}^{*}$ to induce effort and thereby raise divisional payoff in period 2 by $\bar{e} I_{2}$. However, if (14) holds, $H$ has no incentive to do so. Condition (15) follows similarly.

In any separating equilibrium type $H$ selects its full information allocation $\alpha_{H}^{*}=1$ and distributes all funds to division $A$. The intuition is that any other putative equilibrium allocation $\alpha_{H}^{*} \neq 1$ would motivate type $H$ to deviate from the equilibrium strategy and raise allocations to the more profitable division A without having further negative effects on managers' effort levels. ${ }^{14}$

Using this finding, $H$ 's incentive compatibility constraint, condition (14), simplifies to:

$$
\Pi_{H, 1}^{*}-\Pi_{H, 1}\left(\alpha_{L}^{*}\right) \geq \bar{e} I_{2}
$$

\footnotetext{
${ }^{14}$ Any putative equilibrium allocation $\hat{\alpha}_{H} \neq 1$ would yield a strictly smaller payoff than a putative out-of equilibrium strategy $\alpha_{H}^{*}=1$ considering even most "favorable" off-equilibrium beliefs to sustain an equilibrium, namely $\eta<2 \frac{c}{\nu I_{2}}$ (which would induce $e_{i}=0$ ), since: $\Pi_{H, 1}\left(\hat{\alpha}_{H}\right)+\Pi_{H, 2}^{*}<\Pi_{H, 1}\left(\alpha_{H}^{*}=\right.$ 1) $+\Pi_{H, 2}^{*}=\Pi_{H, 1}^{*}+\Pi_{H, 2}^{*}$.
} 
Inequality (16) has a straightforward interpretation. For $\alpha_{L}^{*}$ to be incentive compatible such that $H$ prefers its own allocation $\alpha_{H}^{*}=1, H$ 's first period cost from inefficient investment, $\Pi_{H, 1}^{*}-\Pi_{H, 1}\left(\alpha_{L}^{*}\right)$, must be larger than its second period gain, $\bar{e} I_{2}$, from mimicking a type $L$ headquarters.

We now analyze type $L$ 's incentive-compatibility constraint. A type $L$ headquarters would never want to imitate $H$ since $\alpha_{H}^{*}=1$ makes managers believe that headquarters is type $H$ inducing them to do nothing, which immediately lowers productivity in period 2 by $\bar{e} I_{2}$. At the same time, $\alpha_{H}^{*}$ clearly makes $L$ 's period 1 investment weakly less efficient than any other allocation. Hence, (15) holds for any $\alpha_{L}^{*} \in[0,1]$. Consequently, the sole rationale to move away from its full information optimum and to select separating allocation $\alpha_{L}^{*}$ is to prevent type $H$ to deviate and make pooling sufficiently costly. ${ }^{15}$

However, in order to credibly signal its type, type $L$ generally cannot select arbitrary $\alpha_{L}^{*}$ 's satisfying (16) as for any out-of-equilibrium allocation, there must exist (at least) some belief that would impede type $L$ to deviate from $\alpha_{L}^{*}$. Hence, analogously to the previous analysis of pooling equilibria, to determine the maximum set of admissible $\alpha_{L}^{*}$, we need to maximize over all off-equilibrium allocations to solve for the highest out-of-equilibrium allocation under beliefs that would not induce effort and impose

$$
\Pi_{L, 1}\left(\alpha_{L}^{*}\right)+\Pi_{L, 2}^{*} \geq \max _{\alpha} \Pi_{L, 1}(\alpha)+\Pi_{L, 2}^{*}-\bar{e} I_{2}
$$

which yields

$$
\Pi_{L, 1}^{*}-\Pi_{L, 1}\left(\alpha_{L}^{*}\right) \leq \bar{e} I_{2}
$$

This result has an interesting yet simple interpretation: For $\alpha_{L}^{*}$ to be an equilibrium candidate, $L$ 's cost from inefficient investment in period 1 must be weakly smaller than the productivity gain from defending second period gain from managerial effort. Also, if condition (17) is violated, the cost of inefficient investment relative to $\bar{e} I_{2}$ is "too high", such that type $L$ may be better off not to signal its type.

Using inequalities (16) and (17), we characterize the maximum set of separating equilibrium allocations. In any separating equilibrium, type $H$ 's optimal choice equals its choice under full information, i.e. $\alpha_{H}^{*}=1$. Type $L$, however, chooses an allocation $\alpha_{L}^{*}$ which belongs to the interval $\left[\underline{\alpha}_{L}^{*}, \bar{\alpha}_{L}^{*}\right]$, where $\bar{\alpha}_{L}^{*}$ and $\underline{\alpha}_{L}^{*}$ denote the lower bounds of the interval solving (16) and (17), respectively. For illustration, we resume the case of the

\footnotetext{
${ }^{15}$ Thereby, type $L$ 's ability to separate stems from type $L$ finding inefficient investment marginally less costly than type $H$, while both types of headquarters likewise prefer more effort to less: $\frac{\delta\left[\Pi_{H, 1}(\alpha)-\Pi_{L, 1}(\alpha)\right]}{\delta \alpha}>0$. For type $L$ thus the incentive to separate, namely to defend higher period 2 productivity, and the ability to separate as to low signaling cost are aligned.
} 
previous section in which condition (13) holds and depict the set of separating equilibrium allocations in figure 6 . Hence, $\alpha_{L}^{*}$ is on the interval $\left[\underline{\alpha}_{L}^{*}, \bar{\alpha}_{L}^{*}\right]$, where $\underline{\alpha}_{L}^{*}=0$ and $\bar{\alpha}_{L}^{*}<0.5$.

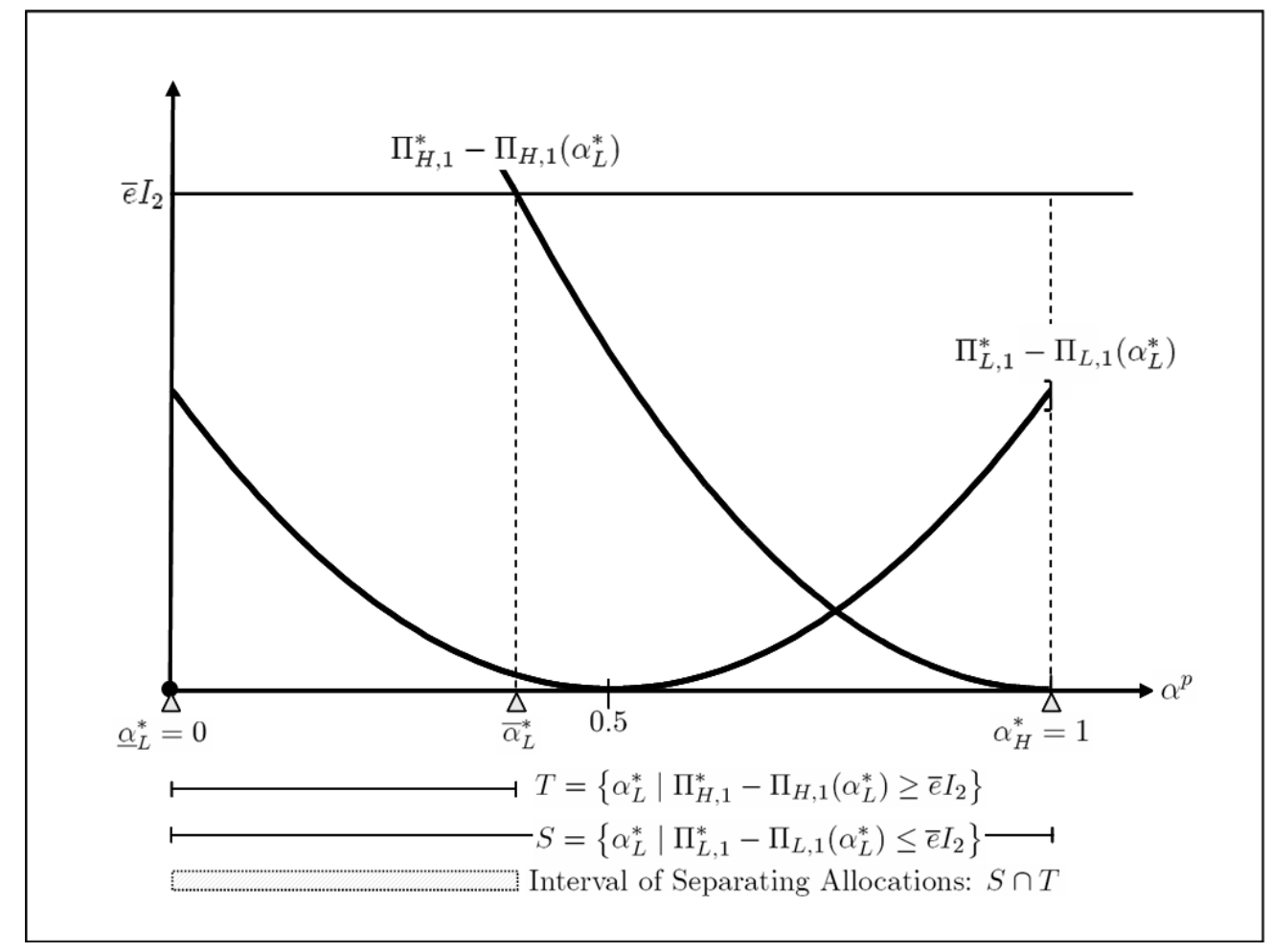

Figure 6: Interval of Separating Allocations $\alpha_{L}^{*}$

\subsubsection{Equilibrium Refinement}

In the previous sections we have shown that there are two kinds of Perfect Bayesian Equilibria in pure strategies for the case in which condition (13) holds. Pooling equilibria are given by $\alpha^{p} \in\left[\underline{\alpha}^{p}, 1\right]$ and separating equilibria by $\alpha_{H}^{*}=1$ and $\alpha_{L}^{*} \in\left[0, \bar{\alpha}_{L}^{*}\right]$, where $\underline{\alpha}^{p}=\bar{\alpha}_{L}^{*}=z<0.5$. We show that applying the notions of Undefeated Equilibrium and $D 1$ eliminates all equilibria but the pooling equilibrium in which $\alpha^{p}=0.5$.

The intuition underlying our solution concept is straightforward. We require headquarters and managers to reason "forward" such that starting from a conjectured equilibrium any deviation would provoke managers to form beliefs according to some hierarchy. By applying Undefeated Equilibrium, we require that initially managers interpret an off-equilibrium allocation as an attempt by some type of headquarters to consciously shift to another, preferred equilibrium and as a consequence adjust off-equilibrium beliefs accordingly. If such interpretation is not possible, managers ask which of headquarters' type is more likely to gain from this deviation compared to the conjectured equilibrium, applying the notion of $D 1$. Once all off-equilibrium beliefs have been restricted according to this hierarchy, a conjectured equilibrium is reasonable only if neither of informed headquarters' 
types has an incentive to deviate.

Applying the refinement requires several steps. It is helpful to recall that both, pooling allocations $\alpha^{p}$ and type $L$ 's separating allocations $\alpha_{L}^{*}$, induce managerial effort $\bar{e}$. First, diminishing returns to scale and $L$ 's optimum at $\alpha=0.5$ make any separating equilibrium allocation $\alpha_{L}^{*}<z$ strictly less profitable from type $L$ 's perspective than the least-cost separating equilibrium in which $\alpha_{L}^{*}=z$. Hence $L$ has an incentive to shift to its least-cost separating equilibrium which therefore defeats any other separating equilibrium. Second, notice that if headquarters is of type $L$, marginal productivities of divisions $A$ and $B$ are equal which implies that any capital allocation $\alpha=\bar{\alpha}$ is payoff-equivalent to an allocation $\alpha=1-\bar{\alpha}, \bar{\alpha} \in[0,1]$. Hence, pooling equilibria at $\alpha^{p}>1-z$ are not reasonable - if headquarters turns out to be $L$, the separating equilibrium at $\alpha_{L}^{*}=z$ yields a strictly higher payoff to this type. Third, consider any conjectured pooling equilibrium in which $\alpha^{p}<0.5$ and a deviation to $\alpha=0.5$. Managers infer that the pooling equilibrium at $\alpha^{p}=0.5$ is being played as both types' payoff function is strictly increasing on the interval $[z, 0.5]$. Since pooling at $\alpha^{p}=0.5$ also makes either type strictly better off than the least cost separating equilibrium, the latter is also defeated. Undefeated Equilibrium therefore leaves an interval of pooling equilibria $\alpha^{p} \in[0.5,1-z]$.

Let us now show that pooling equilibria at $\alpha^{p} \in(0.5,1-z]$ do not survive $D 1$. Consider any conjectured Undefeated Equilibrium on this interval and also a deviation to $\bar{\alpha}=0.5$. Following D1, managers immediately eliminate $H$ as the potential defector. By defecting, type $H$ strictly loses regardless of managers' beliefs (and corresponding effort levels) as cost of inefficient investment increases while managerial effort in equilibrium is already at maximum. In other words, the set of managers' best responses that make $H$ deviate is empty. On the other hand, type $L$ clearly deviates to $\bar{\alpha}=0.5$ (its full information optimum), if managers form a belief that causes managers to provide effort. Therefore, D1 requires that managers' beliefs following such defection should put all the weight on type $L$, which in turn forces type $L$ to deviate from the conjectured pooling equilibrium.

Finally, we show that there exists a unique Undefeated Equilibrium which satisfies D1 - the pooling equilibrium at $\alpha^{p}=0.5$. By following its equilibrium strategy, $L$ is strictly better off than with any other allocation regardless of managers' beliefs; whereas $H$ may obtain a higher payoff by defecting to $\bar{\alpha} \in(0.5,1]$ if $\bar{\alpha}$ causes managerial effort only. Consequently, since $H$ has a greater incentive to allocate $\bar{\alpha}$ (whereas $L$ has none), D1 requires that the posterior belief conditioned on $\bar{\alpha}$ should be concentrated on type $H$. This argument in fact restricts off-equilibrium beliefs but does not rule out the equilibrium. $H$ prefers to stick to the equilibrium since any allocation $\bar{\alpha}$ induces managers to reduce effort and condition (13) holds. 


\subsubsection{Equilibrium Implications and Results}

The following proposition summarizes the results from the previous section.

Proposition 2 Let $p(L)=\mu>2 \frac{c}{\nu I_{2}}$.

a) If $\Pi_{H, 1}^{*}-\Pi_{H, 1}\left(\alpha^{p}=0.5\right)<\bar{e} I_{2}$, there is a unique (Undefeated Equilibrium and D1) pooling equilibrium outcome, in which both types of headquarters evenly split funds according to $\alpha^{p}=0.5$. Equilibrium strategies are given by

$$
\left(\alpha_{1}^{*},\left(e_{A}^{*}, e_{B}^{*}\right), \alpha_{2}^{*}\right)= \begin{cases}\left(\frac{1}{2},(\bar{e}, \bar{e}), \frac{1}{2}\right) & \text { if headquarters is type } L \\ \left(\frac{1}{2},(\bar{e}, \bar{e}), 1\right) & \text { if headquarters is type } H\end{cases}
$$

First-period allocation $\alpha^{p}$ is uninformative with respect to relative divisional profitability, hence managers' beliefs equal their prior, $p\left(L \mid \alpha^{p}\right)=p(L)=\mu$. Managers assign zero probability to type $L$ following an off-equilibrium deviation on the interval $\bar{\alpha} \in(0.5,1]$ and form arbitrary beliefs otherwise.

Equilibrium payoffs to headquarters equal

$$
\begin{array}{ll}
\Pi_{L, 1}^{*}+\Pi_{L, 2}^{*} & \text { if headquarters is type } L \\
\Pi_{H, 1}\left(\alpha^{p}=0.5\right)+\Pi_{L, 2}^{*}+\bar{e} I_{2} & \text { if headquarters is type } H
\end{array}
$$

b) If $\Pi_{H, 1}^{*}-\Pi_{H, 1}\left(\alpha^{p}=0.5\right)>\bar{e} I_{2}$, there is a unique (Undefeated Equilibrium and D1) separating equilibrium outcome which is the complete information outcome as described in Proposition 1.

Proposition 2 establishes that the incentive of headquarters to not disclose information on divisional productivity via capital allocation can be important enough to dominate the equilibrium outcome. This incentive is sufficiently strong when heterogeneous productivity across divisions is not too likely ex ante. Then, uninformed managers expect their effort to have an impact on second-period capital allocation and engage in valueenhancing activities regardless of their relative rank with respect to productivities. In addition, the benefit of increased second-period capital productivity must be sufficiently large to a type $H$ headquarters compared to first-period cost from inefficient investment such that pooling is profitable.

Corollary 1 Under the assumptions of Proposition 2a, headquarters with private information on relative profitability of their divisions allocate first-period funds $I_{1}$ evenly according to $\alpha^{p}=0.5$, whereas capital allocation under full information is characterized by $\alpha_{1}^{*}=0.5$ if headquarters is type $L$ and $\alpha_{1}^{*}=1$ if headquarters is type $H$. 
Corollary 1 follows from Propositions 1 and 2 and implies socialism in internal capital markets. Our model predicts that if investment opportunities across divisions are diverse as headquarters is type $H$, the firm takes capital away from its more profitable division, hence allocating too little to its "higher $q$ " division $A$ and too much to its "lower $q$ " division $B$. Our model predicts a pooling equilibrium when the benefits to pooling are large for headquarters. The following result describes how these benefits are related to the relative capital productivity of divisions $A$ and $B$ and the levels of investment in the two periods.

Corollary 2 The pooling equilibrium under incomplete information renders a type $H$ headquarters better off than its full information equilibrium. For type $L$ headquarters, equilibria under complete and incomplete information are payoff-equivalent.

Proof. Equilibrium outcome under complete and incomplete information for type $H$ yields $\Pi_{H, 1}\left(\alpha^{p}=0.5\right)+\Pi_{H, 2}^{*}+\bar{e} I_{2}$ and $\Pi_{H, 1}^{*}+\Pi_{H, 2}^{*}$, respectively; whereas payoff equals to $\Pi_{L, 1}^{*}+\Pi_{H, 2}^{*}$ for type $L . \Pi_{H, 1}\left(\alpha^{p}=0.5\right)+\Pi_{H, 2}^{*}+\bar{e} I_{2}>\Pi_{H, 1}^{*}+\Pi_{H, 2}^{*}$ follows from condition (13).

Private information hence improves equilibrium outcome to headquarters. From the perspective of the two-period investment cycle, either type of headquarters is (weakly) better off following a nondisclosure (via capital) policy, which implies that the pooling equilibrium outcome dominates the full information outcome for both homogeneous and heterogeneous relative productivities. Having the opportunity to withhold information about true relative capital productivities thus raises firm value.

Corollary 3 Under the assumptions of Proposition 2a, ceteris paribus, an increase in $I_{2}$ and $\bar{e}$ and a decrease in $I_{1}$ and $\bar{x}$ expand the set of remaining parameter values that yield the pooling equilibrium outcome as described in Proposition $2 a$.

Proof. $\bar{\Pi}=\Pi_{H, 1}^{*}-\Pi_{H, 1}\left(\alpha^{p}=0.5\right)-\bar{e} I_{2}=\frac{1}{2} \bar{x} I_{1}-\frac{1}{4} k I_{1}^{2}-\bar{e} I_{2} \Rightarrow \frac{\partial \bar{\Pi}}{\partial \bar{x}}>0, \frac{\partial \bar{\Pi}}{\partial I_{1}}>0, \frac{\partial \bar{\Pi}}{\partial \bar{e}}<0$, $\frac{\partial \bar{\Pi}}{\partial I_{2}}<0$ since $\bar{x} \geq k I_{1}$ and $\bar{x}, I_{1}, k>0$.

Corollary 2 implies that pooling occurs if $I_{1}$ compared to $I_{2}$ is low and $\bar{x}<\bar{x}_{\max }$, where $\bar{x}_{\max }$ solves $\Pi_{H, 1}^{*}-\Pi_{H, 1}\left(\alpha^{p}=0.5\right)=\bar{e} I_{2}$. 


\section{Discussion of Results and Empirical Implications}

In this section we discuss our model's results. Our theory of internal capital markets yields a number of empirical implications.

a) Socialism in Internal Capital Markets

Corollary 1 implies socialism in internal capital markets. Our model predicts that multibusiness firms bias their investment levels in favor of divisions with weaker investment prospects. This distortion of capital allocations is documented in empirical studies by Scharfstein (1998), Shin and Stulz (1998) and Rajan, Servaes and Zingales (2000). Compared to previous research, our model provides an alternative explanation for socialistic internal capital market allocations. Our key argument is that headquarters uses funds to control managerial expectations about prospective assets under control which affects effort levels and future capital productivities. To boost managerial effort, headquarters distributes capital more evenly than it would, if information were distributed symmetrically.

\section{b) Relatedness of Businesses and Information Sharing}

In Corollary 2 we raise the point that equal capital allocation in equilibrium is noninformative about the relative performance of divisions and either type of headquarters is (weakly) better off compared to full information. Consequently, our model also provides an argument for limiting access to information on other divisions' business opportunities and in this respect for strategic lack of transparency within multi-business firms. It also may serve as a rationale for why firms may oppose regulation that increases transparency about individual units such as detailed segment reporting.

This argument leads to the question under which circumstances it is more feasible to withhold information about relative performance from divisional managers. This opportunity may be more pronounced when multi-business firms operate strictly unrelated businesses and managers do not operate in the same or similar industries assuming that managers report investment quality directly to headquarters. In this case, predictions on other division's investment opportunities and hence relative performance assessment may be more challenging to achieve as managers may count less on their own knowledge with respect to industry, technology, products and regulation derived from own operations. This implication is consistent with the empirical study by Khanna and Tice (2001), whose findings suggest that firms with operations in related industries do not appear to subsidize weaker divisions. 


\section{c) Levels of Investments}

An immediate empirical implication emerges from Corollary 3. Pooling, hence evenly distributed capital investment, should be prevalent in periods in which available internal funds are scarce compared to future periods. Then, inefficient investment is less significant compared to the gain from inducing effort to be utilized in upcoming periods in which funds are less constrained, and sacrificing short run profits is less costly relative to long term profits. The argument points in two directions. First, we may interpret socialistic investment behavior as one action to motivate search for new opportunities during periods when funds are temporarily constrained $\left(I_{1}\right)$. Second, pooling may also enhance the incentives to strongly exploit growth opportunities and prepare for periods of large investments $\left(I_{2}\right)$, for instance, prior to capacity expansions and market entry.

\section{d) Industry Shocks and Diversity of Investment Opportunities}

Corollary 3 also implies that a pooling equilibrium is less likely if $\bar{x}$ is especially large and divisions are strongly heterogenous with respect to profitable investment opportunities. For instance, consider a type $H$ multi-business firm which allocates capital evenly. Suppose also that one division is affected by an exogenous industry shock which alters relative investment prospects in favor of division $A$. Industry shocks may include innovations, deregulation, policy changes, or a significant change in input cost. As a consequence, relative difference in investment prospects $\bar{x}$ may increase such that $\Pi_{H, 1}^{*}-\Pi_{H, 1}\left(\alpha^{p}=0.5\right)>$ $\bar{e} I_{2}$. Then, our model predicts that headquarters is expected to move to another equilibrium - the separating equilibrium with firm investing as under full information. In fact, separation which is that all funds $I_{1}$ are used for investments in a firm's strongest division (provided that divisions are heterogeneous) appears to be established when firms reorganize their businesses in cash-generating/low growth and cash-consuming/high growth businesses. For instance, GE views their portfolio as two distinct groups: Cash Generators provide strong cash flow to the Growth Engines, businesses with many profitable investment opportunities and strong growth [see General Electric, Annual Report 2003].

\section{Extension}

So far, we have focused on the situation in which divisional managers exert effort in case they do not learn anything from period-1 capital allocation (equation (10)); in other words, when their posterior belief regarding the probability of facing a type $L$ headquarters equals their prior belief. In this section, we briefly discuss the situation in which $p(L)=\mu<2 \frac{c}{\nu I_{2}}$ 
Then, as long as $\frac{1}{2} \bar{x} I_{1}-\frac{1}{4} k I_{1}^{2}<\bar{e} I_{2}$ holds, there does not exist a pooling equilibrium as pooling is not an attractive proposition for either type of headquarters. Also, the complete information outcome as characterized in Proposition 1 is not an equilibrium outcome as a type $H$ headquarters has an incentive to mimic type $L$ headquarters' complete information allocation of $\alpha_{L}=0.5$. We omit a detailed analysis here, but it can be shown that under some additional parametric restrictions there exists a unique separating equilibrium outcome in which $\alpha_{L}^{*} \in(0,0.5)$ and $\alpha_{H}^{*}=1$. Type $L$ headquarters allocates more period-1 capital to division $B$ than to division $A$ despite equal capital productivities in order to render it too costly for type $H$ headquarters to mimic its allocation.

This result implies that on average division $B$ obtains a larger period-1 capital allocation than it would under complete information. Therefore, the internal capital market displays "socialistic" behavior also under circumstances in which pooling does not lead to effort provision.

One difference to the pooling equilibrium outcome characterized in Proposition 1 is that in the separating outcome described here ex ante expected profits are lower than under complete information. This implies that ex ante headquarters has an incentive to commit to creating transparency about investment opportunities across divisions.

\section{Conclusion}

This paper provides a novel explanation for the socialistic allocation of resources in internal capital markets based on asymmetric information between headquarters and divisional managers about the relative levels of capital productivity across divisions. Headquarters may choose an even capital allocation initially in order to create competition for future funds which in turn improves future capital productivity. 


\section{References}

[1] Aghion, P. and Tirole, J., 1997. Formal and Real Authority in Organizations. The Journal of Political Economy, 105(1), 1-29.

[2] Banks, J.S. and Sobel, J., 1987. Equilibrium Selection in Signaling Games. Econometrica, 55(3), 647-661.

[3] Bernardo, A.E., Luo, J., and Wang, J.J., 2006. A Theory of Socialistic Internal Capital Markets. Journal of Financial Economics, 80(3), 485-509.

[4] Brusco, S. and Panunzi, F., 2005. Reallocation of Corporate Resources and Managerial Incentives in Internal Capital Markets. European Economic Review, 49(3), 659-681.

[5] Cho, I. and Kreps, D.M., 1987. Signaling Games and Stable Equilibria. Quarterly Journal of Economics, 102(2), 179-221.

[6] De Motta, A., 2003. Managerial Incentives and Internal Capital Markets. The Journal of Finance, 58(3), 1193-1220.

[7] Fudenberg, D. and Tirole, J., 1991. Perfect Bayesian Equilibrium and Sequential Equilibrium. Journal of Economic Theory, 53(2), 236-260.

[8] Gautier, A. and Heider, F., 2006. The Benefit and Cost of Winner-Picking: Redistribution vs. Incentives. Working Paper.

[9] Gertner, R.H., Scharfstein, D.S., and Stein, J.C., 1994. Internal versus External Capital Markets. Quarterly Journal of Economics, 109(4), 1211-1230.

[10] Goel, A.M., Nanda, V. and Narayanan, M.P., 2004. Career Concerns and Resource Allocation in Conglomerates. Review of Financial Studies, 17(1), 99-128.

[11] Harris, M. and Raviv, A., 1996. The Capital Budgeting Process: Incentives and Information. Journal of Finance, 51(4), 1139-1174.

[12] Hart, O. and Moore, J., 1995. Debt and Seniority: An Analysis of the Role of Hard Claims in Constraining Management. The American Economic Review, 85(3), 567585.

[13] Inderst, R. and Laux, C., 2005. Incentives in Internal Capital Markets. RAND Journal of Economics, 36(1), 215-228. 
[14] Khanna, N. and Tice, S., 2001. The Bright Side of Internal Capital Markets. The Journal of Finance, 56(4), 1489-1528.

[15] Kohlberg, E. and Mertens, J.F., 1986. On the Strategic Stability of Equilibria. Econometrica, 54(5), 1003-1037.

[16] Kreps, D.M. and Wilson, R., 1982. Sequential Equilibria. Econometrica, 50(4), 863894.

[17] Lazear, E.P. and Rosen, S., 1981. Rank-Order Tournaments as Optimum Labor Contracts. Journal of Political Economy, 89(5), 841-864.

[18] Mailath G. J., Okuno-Fujiwara Masahiro, and Postlewaite A., 1993. Belief-Based Refinements in Signalling Games. Journal of Economic Theory, 60(2), 241-276.

[19] Maksimovic, V. and Phillips, G., 2002. Do Conglomerate Firms Allocate Resources Inefficiently Across Industries? Theory and Evidence. The Journal of Finance, 57(2), 721-767.

[20] Maksimovic, V. and Phillips, G.M., 2007. Conglomerate Firms and Internal Capital Markets, in Eckbo, B.E. (ed.): Handbook of Corporate Finance: Empirical Corporate Finance, North-Holland, Amsterdam 423-477.

[21] Mintzberg, H., 1975. The Manager's Job: Folklore and Fact. Harvard Business Review, 53(4), 49-61.

[22] Nöldeke, G. and Samuelson, L., 1997. A Dynamic Model of Equilibrium Selection in Signaling Markets. Journal of Economic Theory, 73(1), 118-156.

[23] O'Keeffe, M., Viscusi, W.K. and Zeckhauser, R.J., 1984. Economic Contests: Comparative Reward Schemes. Journal of Labor Economics, 2(1), 27-56.

[24] Rajan, R., Servaes, H., and Zingales, L., 2000. The Cost of Diversity: The Diversification Discount and Inefficient Investment. Journal of Finance, 55(1), 35-80.

[25] Scharfstein, D.S., 1998. The Dark Side of Internal Capital Markets II: Evidence from Diversified Conglomerates. NBER Working Paper No. 6352

[26] Scharfstein, D.S. and Stein, J.C., 2000. The Dark Side of Internal Capital Markets: Divisional Rent-Seeking and Inefficient Investment. Journal of Finance, 55(6), 25372564 .

[27] Shin, H. and Stulz, R.M., 1998. Are Internal Capital Markets Efficient? Quarterly Journal of Economics, 113(2), 531-552. 
[28] Stein, J.C., 1997. Internal Capital Markets and the Competition for Corporate Resources. Journal of Finance, 52(1), 111-133.

[29] Stein, J., 2002. Information Production and Capital Allocation: Decentralized versus Hierarchical Firms. The Journal of Finance, 57(5), 1891-1921. 